\title{
A FACTOR MODEL OF TERM STRUCTURE SLOPES IN EUROCURRENCY MARKETS
}

\author{
Emilio Domínguez ${ }^{1}$ \\ A Ifonso Novales ${ }^{2}$
}

M arch 2001

\section{ABSTRACT}

Keywords: Term structure of interest rates, term structure slope, Principal components, Eurocurrencies JEL Classification: E37, E43

1. Departamento de Fundamentos del A nálisis E conómico. Universidad Pública de Navarra. Pamplona. Spain.

2. Departamento de E conomía Cuantitativa. Universidad Complutense. M adrid. Spain. 


\section{INTRODUCTION}

One of the main difficulties in risk management of fixed income portfolios is the high dimensionality of the term structure of interest rates, which precludes probability evaluation of future movements in the yield curve unless interest rate fluctuations can be explained by changes in a few factors. This has motivated for a number of years a variety of research lines attempting to characterize a reduced number of factors summarizing yield curve shifts. A research line has searched for a small subset of relevant maturities with the property that fluctuations in their associated interest rates can explain a good deal of the fluctuations in interest rates over the whole term structure. A nother line has focused on the implications that the existence of a reduced number of factors has on portfolio immunization.

This paper departs from previous research in dealing with dimensionality reduction in the space of international term structure slopes. Recent empirical work has documented the existence of information in the slope of the term structure which is relevant to forecast future changes in economic activity, and it is additional to information in past economic activity, inflation, or in any leading indicator index [see Estrella and Hardouvelis (1991), Stock and W atson (1988), H ardouvelis (1994) and Plosser and Rouw enhorst (1994), among others]. This implies that a good forecasting model of term structure slopes could be helpful to anticipate changes in economic activity with an even longer anticipation.

We discuss two related questions in this paper: first, whether a good forecasting model can be found for term structure slopes in different currencies. Second, assuming that such models exist, we test for whether fluctuations in a vector of international term structure slopes can be summarized by changes in a few of them. This would greatly simplify the problem of producing slope forecasts when searching for trend changes in economic activity across countries, since it would only be necessary to forecast the smaller subset of chosen factors. We start by characterizing the factors explaining the vector of slopes across the currencies included in our sample, to then test for the quality of slope forecasts obtained from factor model forecasts, as compared with forecasts obtained from univariate models.

Interest rates should be expected to be correlated across different currencies, since it is widely believed that monetary policy actions in some countries, particularly in the US, lead to similar interventions in other countries. In addition, increased monetary policy coordination, as it was the case in Europe prior to the constitution of the euro area, has led to common interest rate fluctuations among countries in the European U nion. However, since monetary authorities in all countries determine very short-term interest rates, we should expect to see high correlations in the shorter end of the term structure, but not necessarily among longer-term rates. Correlations between slopes would emerge from correlations between short-term rates if interest rates at longer maturities were roughly constant (they are much less volatile than short-term rates in all countries). A view that the spread between long- and short-term interest rates is roughly constant over time would also lead from correlations among interest rates at short 
maturities to correlations among slopes. However, none of these views is fully realistic, and deviations from them would produce lower correlations among slopes than among short-term interest rates.

To search for term structure slope factors, we use a principal components technique, and estimate the projections of each slope on a subset of principal components. W e obtain forecasts for the principal components out of univariate models, which translate into forecasts for term structure slopes through their projections on the subset of principal components. These forecasts are compared with those obtained from univariate models for the slopes.

We describe in Section 2 some sample correlations among slopes in different currencies. Principal components are presented and interpreted in Section 3. Section 4 is devoted to forecast evaluation, and the paper closes with a summary of results and some questions open for further research.

\section{RELATIONSHIPS AMONG TERM STRUCTURE SLOPES ACROSS EUROCURRENCIES}

Euro-currency markets originated in the $50^{\prime} s$ to take advantage of the fact that US legislation allowed for deposits kept abroad in a currency other than the US dollar, not to be subject to reserve requirements. This stimulated the development of markets in bank deposits in a number of eurocurrencies, with basis in London. Euro-currency markets matured right after the successive crisis in oil prices during the 70 's, when oil producing countries invested their resulting current account surplus in them, and negotiated volumes have continuously increased since then. In the L ondon eurocurrency market, interest rates are quoted for deposits denominated in a variety of currencies and maturities. Being off-shore, deposits in the eurocurrency market share some important characteristics, like the fiscal treatment of returns or the timing of return payments, and they are not subject to possible government interventions like capital controls, which makes their observed returns more comparable than interest rates from domestic markets. We use monthly data on euro-rates for the US dollar, Japanese yen, Deutsche mark, British pound, French franc and Swiss franc for 1979:1-1998: 12 and compute their term structure slope as the difference between returns on 12- and 1-month deposits.

A number of papers have provided evidence that euro-returns on deposits in different maturities and currencies are related, although the appropriate interpretation of these relationships is still open to discussion. Based on 1979-1988 data on euro-rates on 3-month deposits, K arfakis and M oschos (1990) found evidence of a Deutsche mark-zone, reflected in a Granger-causality structure running from the 3-month rate on the D eutsche mark, to those on other european currencies. However, deGrauwe (1989), vonH agen and F ratiani (1990) and Katsimbris and M iller (1993) argued against that result for not taking properly into account the common effect of a third factor, US interest rates. These authors argue for: a) a quite more complex set of interactions among interest rates across countries, and b) an almost equally important role for Deutsche mark and U S interest rates in determining those in European M onetary System (E M S) countries. With an enlarged 
sample for 1979-1997, Domínguez and N ovales (2000) have found interest rates on different currencies at a given maturity to be cointegrated. These authors have also found clear evidence in the pre-1999 years that Deutsche rates were causal prior to those in other EMS countries, in line with the results of Karfakis and M oschos (1990).

L eaving aside the discussion on how to interpret these results, the existence of long-run relationships among interest rates at a same maturity across currencies does not guarantee by itself that an improvement in forecasting slopes will follow. Cointegration among returns means that they share the same long-run trend, but it leaves open the possibility that short-term fluctuations may be unrelated. As a consequence, correlations among short-term rates across countries, as well as correlations among their long-term rates will not necessarily be large, and correlations among their respective slopes might be even lower.

We analyze the possible connections among term structure slopes across different Eurocurrencies, defined as the spread between returns on 12- and 1-month deposits, $r_{t}^{12}-r_{t}^{1}$. We will consider the full sample, as well as the 1984-98 subsample due to the large interest rate volatility over 1979-84. A ugmented DickeyFuller (ADF) tests at the 5\% significance level [Table 1] for the more stable 1984-1998 subsample lead to rejecting the unit root hypothesis in term structure slopes for all currencies, even though graphs for this period [not shown] could throw some doubt about their stationarity.

The relationships among interest rates in european countries even before their common membership to the EM S has produced significant correlations among term structure slopes as well, as shown in Table 2 for 1984-1998 and 1991-1998. Correlations have been higher during the more recent period, due to an increased coordination of monetary policies. Surprisingly, slopes for the US dollar, yen and Deutsche mark do not show large correlations prior to 1999. In fact, the yen slope presents its higher correlations with the slopes of the British pound and the Swiss franc. Contrary to an increased globalization of international financial markets, slopes for the yen and the US dollar seem to have grown increasingly independent in the second part of the sample.

Since the large volatility over 1979-84 influences estimates, leading to a loss in forecasting performance, we just report in what follows results obtained with the more stable 1984-98 subsample.

\section{A PRINCIPAL COMPONENT ANALYSIS OF EUROCURRENCY SLOPES.}

The eigenvalues of the covariance matrix of slopes are $342.8,71.6,70.8,16.7$ and 12.6 , showing that the first principal component explains almost $61 \%$ of the variance in the set of term structure slopes for the six currencies in our sample. The second and third components explain an additional $12 \%$ each, with the fourth component explaining $9 \%$ of the joint fluctuation in slopes. There is some doubt as to whether three or four principal components should be used to summarize slope fluctuations in the six countries in our sample, with a difference of explaining either $85 \%$ or $94 \%$ of the joint fluctuations in the vector of slopes. 
Table 3.a shows the eigenvectors of the covariance matrix of slopes, defining their principal components. Unfortunately, it is not very simple to identify the dominant slopes in the sample by just a direct reading of the estimated eigenvectors. To actually identify the estimated components, we also provide in Table 3 estimated regressions of each slope using as explanatory variables either a single principal component, or a subset of them. Panel $b$ in the table shows estimated R-squared coefficients of the regressions of slopes on individual components. The first regression in panel $\mathrm{c}$ is the same as in the first panel. The second regression in panel $c$ uses the first two components as explanatory variables, the next regression uses the first three components as explanatory variables, and so on.

The first component seems to incorporate information on the slopes from markets in the euro zone, being highly correlated with french franc and deutsche mark slopes, with R-squares of .774 and .758, respectively. Besides, its correlation with the swiss franc slope is also relatively high, at.494. The second component shows its highest correlation with the UK slope, all others being much smaller. A similar interpretation for the first two components is achieved by examining the scatter graphs in Figures 1 and 2 . The third and fourth principal components do not show high correlation with any slope, so it is hard to interpret them this way. However, in the regressions that accumulate principal components as explanatory variables, we see that the third component adds significant explanatory power for the deutsche mark slope, whose cumulative R-squared increases by $30 \%$, and for the swiss franc, for which the increase is of $22 \%$. It also produces a significant increase, of almost $17 \%$, in the R-squared associated to the french franc slope. As it was the case with the first component, this third component seems to also summarize fluctuations in european markets. However, it must be a completely different kind of information since, as it is well known, principal components are uncorrelated with each other by construction.

Surprisingly, we discover in the last regression in panel $c$ that the fourth factor contains very significant explanatory power for the US slope, summarizing fluctuations in that market which are independent from those experienced by european slopes. There is no specific information from the yen area in the first four components. It would most likely appear in further components, at least one of which should be expected to be highly correlated with the yen slope. There is also some residual information from the swiss market not captured in the first four components which would also show up in the remaining two components.

\section{PREDICTING TERM STRUCTURE SLOPES WITH FACTOR MODELS.}

Since forecasting future slope values could be quite interesting for reasons already exposed in the Introduction, we analyze in this section whether the estimated principal components can be used not only to fit fluctuations in slopes, but to anticipate their future behavior as well. The possibility that principal components may provide good forecasts is intuitively appealing, since the idea of the principal components technique is to reduce the dimensionality in a vector of variables. However, the question is quite demanding, 
since principal components are designed to fit the data, but do not incorporate any dynamic feature.

We check the possibility that sensible slope forecasts can be obtained by forecasting a short number of factors, using as a benchmark for comparison AR (3) univariate models for each slope,

$$
r_{1 t}^{12}-r_{1 t}^{1}=\alpha+\sum_{i=1}^{3} \beta_{i}\left(r_{1 t-i}^{12}-r_{1 t-i}^{1}\right)+\varepsilon_{t}
$$

where $r_{11}, j=1,12$ denotes the one and twelve month interest rates in the affected currency, from which forecasts are readily obtained. As a proposed alternative, we use a least-squares projection of a given term structure slope on a few principal components, used as factors, to forecast the slope. Forecasts for each principal component in the projection are obtained by fitting again univariate AR (3) models. Hence, in our proposed alternative, forecast errors from univariate principal components models add to errors from the estimated slope projections.

Even though we did not perform a systematic search for a best model, the AR (3) is flexible enough to accommodate a cyclical behavior (if it has two complex roots), as well as a quite permanent component, if it existed (which it would show as a real root close to the unit circle).

We report estimates for the 1984-1997 sample, since the higher interest rate volatility at the beginning of the sample produces a significant loss of efficiency in estimation and a small deterioration in forecasting performance. Estimated univariate models are presented in the left column of each panel in Table 4, while columns to the right show the estimated principal component models. We leave 1998 data aside, to be used for forecast evaluation.

Estimates in Table 4 show that AR(3) models are adequate for each slope. Even though they may be an overparameterization, as indicated by some non-significant coefficients, we chose to maintain the three lags so as to avoid discretional intervention in model design. We checked that this choice does not lead to any significance deterioration in forecasting performance. Not surprisingly, our estimates show that principal components provide a good contemporaneous fit for the term structure slopes. M ore striking is the fact that the principal components regression provides a much better fit than the $A R(3)$ model, $R$-squared values being about 20\% higher on average, with a corresponding decrease in the SEE. This points out to the fact that simultaneity is more important than dynamic effects in determining the time behavior of any term structure slope. That is, cross-country effects seem to be even more important than time effects in explaining fluctuations in term structure slopes.

However, a better fit does not necessarily come together with an improvement in forecasting ability, so we discuss now the extent to which the in-sample explanatory power of the principal components for term structure slopes across countries can actually be used to improve upon univariate forecasts.

To establish the comparison, we compute forecasts for the term structure slope in each currency from an $A R(3)$ specification, as well as from combining the projection of each slope on a subset of principal components, with $A R(3)$ forecasts for each component [U sing estimates in Table 4]. This is quite a strict request, since we are substituting the dynamics of the principal components for the dynamics of the own slope. Besides, specially when forecasting one period ahead, we are not taking advantage of the previous data on the 
slope as the AR(3) model does but, rather, forecasts for the principal components are used.

The forecasting exercise consisted on estimating each model with data up to December 1997 and obtaining forecasts over 1998. We computed static and dynamic forecasts. Static forecasts are one-step-ahead predictions, which use actual values in the AR(3) models, but one-step ahead forecasts in the principal components model. Here is where the least-squares projections on the principal components are at a clear disadvantage. Dynamic forecasts are once-and-for-all predictions for the twelve months of 1998, calculated with models estimated using data up to December 1997. As we ran out of actual data for the lagged slope being predicted in dynamic forecasting from univariate models, we use previously obtained forecasts. A gain, in the principal component projections, forecasted data are used at all time periods. Clearly, dynamic forecasting always produces bigger forecast errors that static forecasting, since the latter exercise projects over the whole 1998 using only data up to December 1997.

Percent R oot M ean Square E rrors are not advisable in this forecasting exercise, since the slope often becomes small in absolute value, to the point that even acceptable forecast errors might produce huge percent errors for a single period, dominating the value of any time aggregate forecasting performance indicator. Hence, we will use their versions in absolute terms. We provide in Table 5 the $M$ ean and M edian A bsolute Errors, the Root M ean Square Error (RM SE), and Theil's U -statistic as forecasting performance measures for univariate models as well as for principal component models. A large forecast error in a particular month will tend to produce a high average measure, so that the M edian should be preferred to the M ean A bsolute Error. The left column in each panel contains error measures for univariate forecasts, while the remaining columns show error measures when either one or two principal components are used. Below each currency name, we show the sample average absolute value of each slope over the forecasting horizon, 1998:11998:12, the reference against which forecast statistics should be compared to evaluate forecast performance. Bold figures in Table 5 highlight cases in which the principal components model outperformed the univariate slope model in forecasting.

Statistics in Table 5 show that:

1) median one-step-ahead forecast errors from $A R(3)$ models are, on average, close to one third of the sample mean absolute slope for all currencies, showing that univariate slope forecasts are quite good. The lowest gain is achieved for the yen, although the reduction in forecast error is of $36 \%$,

2) quite strikingly, principal component projections produce slope forecasts which are as good, and sometimes even better, than univariate models. In 29 out of the 48 forecasting performance indicators, the principal component projections beat univariate models in forecasting slopes,

3) only one or two principal components are enough to produce such a good forecasting performance. It is also interesting to point our that, even though there is some marginal explanatory power in further components (as shown in Table 3), adding them to the least-squares projections does not significantly improve forecasting performance.

That the projection on the principal components may forecast at least as well as an $A R(3)$ model is 
quite remarkable since, as we have already pointed out, it does not use actual data in computing slope forecasts, but forecasts of the principal components obtained from their own AR(3) models. This is specially striking in static forecasting, since in that case, we use actual slope data when computing univariate forecasts. Results for static and dynamic forecasting over each of the two semesters of 1998 [not presented here] show similar qualitative results. On the other hand, forecasting results for 1997, based on models estimated with data up to December 1996, show a similar performance.

Furthermore, it is also surprising that it the first principal component by itself can produce slope forecasts as good as those from an AR(3) model for the US dollar and yen since, as discussed in Section 3, this component seems to gather information on slope fluctuations just in the euro area.

Summarizing, we have found strong evidence that reducing the dimensionality of a vector of slopes on one or at most two principal components can be very fruitful for short and medium term slope forecasting for major international currencies. Even though further principal components seem to incorporate information on US dollar and yen slope fluctuations, they are not needed to produce good forecasts even for these currencies, so the reduction in dimensionality leads to a very simple forecasting scheme for term structure slopes. Besides, adding additional factors to the forecasting model does not lead to a significant improvement in forecasting performance.

\section{CONCLUSIONS}

Using Euro-rates monthly data on the British pound, French franc, Deutsche mark, Swiss franc, Japanese yen and US dollar over 1979-1998, we have found that there is the possibility of a large reduction in dimensionality when forecasting term structure slopes. On the one hand, this is a relevant characteristic emerging from significant correlation in term structures across countries. In addition, this result could greatly simplify the task of market analysts interested in detecting in slope changes an anticipation of changes in business cycles.

We have started by computing the principal components in a vector of term structure slopes for major currencies. Somewhat surprisingly, the first principal component, which accounts for $61 \%$ of the joint fluctuation in slopes, is associated to countries in the euro zone. The second component incorporates information from the UK, the third component captures additional information from european currencies, while the fourth component gathers information from the US market not included in the previous components. The last two components incorporate residual information from the swiss franc and yen markets.

This analysis is then used to test the forecasting ability of a factor model based on the estimated principal components to forecast term structure slopes. This is a quite demanding exercise, since principal components are not designed to capture the dynamics in the data set. We first obtain forecasts for the principal components from univariate models, and use them in the representation models for each slope as a function of the chosen factors, to compute slope forecasts. Finally, these are compared with forecasts 
obtained from univariate slope models. We have performed static and dynamic forecasting exercises over the last year in our sample, not used in estimation.

One or two factors (the first principal components) are enough to produce as good forecasts as those obtained from univariate models in most cases. Besides, adding more factors does not lead to a significant gain in forecasting performance. That factors summarizing information in european markets can help predict slopes in the US and J apan is quite striking, as it is the fact that just one principal component can compete with dynamic, univariate models in forecasting term structure slopes. Our

results suggest that cross-country effects are more important than dynamic effects in determining fluctuations in term structure slopes. The extensive correlations among term structures in different currencies can be successfully exploited with just one or two factors, which can also account for the dynamics of term structure slopes. Our results suggests the interest of further research a) at the statistical level, to fully understand the good forecasting performance of principal components, as well as b) from the point of view of characterizing the common features involved in the simultaneous determination of the term structures in different currencies. 


\section{REFERENCES}

de Grauwe, P., 1989, Is the European monetary system a DM -zone?, W orking Paper, CE PR, L ondon.

Domínguez, E., and A.Novales, 2000, Term structure relationships across countries in the eurocurrency markets, manuscript, Universidad Complutense, Madrid.

Estrella, A., and G.A.H ardouvelis, 1991, The term structure as a predictor of real economic activity, The J ournal of Finance $46,555-576$.

Hardouvelis, G.A., 1994, The term structure spread and future changes in long and short rates in the G7 countries, J ournal of M onetary Economics, 25, 59-76.

Kafakis, J.C. and D.M.M oschos, 1990, Interest rate linkages within the European monetary System: A time series analysis, J ournal of M oney, Credit and Banking 22, 388-394.

Katsimbris, G.M. and S.M.Miller, 1993, Interest rate linkages within the European monetary System: Further analysis, J ournal of Money, Credit and Banking 25, 771-779.

Plosser, C.I. and Rouwenhorst, K.G., 1994, International term structures and real economic growth, Journal of M onetary Economics, 22, 133-155.

Stock, J. and M.W atson, 1988, Testing for common trends, J ournal of the American Statistical Asociation, 1097-1107.

V on Hagen, J. and M .F ratiani, 1990, German dominance in the E M S: Evidence from interest rates, J ournal of International M oney and Finance, 18, 817-838. 
Table 1

U nit root tests in eurocurrency term structure slopes.

\begin{tabular}{|c|c|c|c|}
\hline \multirow[t]{2}{*}{ Currency } & \multicolumn{2}{|c|}{ Augmented Dickey-Fuller ${ }^{a}$} & Phillips-Perron statistic \\
\hline & 1979-98 & 1984-98 & $1979-98 \quad 1984-98$ \\
\hline British pound & $-5.31^{* *}(1)$ & $-3.03^{* *}(2)$ & $-5.12^{* *}-3.44^{* *}$ \\
\hline French franc & $-2.74^{* *}(9)$ & $-3.04^{* *}(4)$ & $-6.23^{* *}-3.88^{* *}$ \\
\hline Deutsche mark & $-3.20^{* *}(12)$ & $-2.80^{* *}(0)$ & $-4.45^{* *}-2.80^{* *}$ \\
\hline Swiss franc & $-1.70(9)$ & $-3.23^{* *}(3)$ & $-3.37^{* *}-5.02^{* *}$ \\
\hline J apanese yen & $-5.31^{* *}(12)$ & $-3.44^{* *}(4)$ & $-6.81^{* *}-4.89^{* *}$ \\
\hline US dollar & $-3.59^{* *}(4)$ & $-3.45^{*}(0, c)$ & $-5.66^{* *}-3.45^{*}$ \\
\hline
\end{tabular}

Note: L eft column sample: 1979-98. Right column sample: 1984-98. Critical values at $95 \%$ and $99 \%$ confidence levels: -1.94 and -2.58 , respectively, for models without constant, -2.88 and -3.47 , respectively, for models with constant. An (two) asterisk denotes rejection of the null hypothesis at the 5\% (1\%) significance level. The number of lags used in the regression for the differenced variable when running the Augmented Dickey-Fuller test is shown in brackets. $\mathrm{c}$ denotes that a constant was included in the test regression.

\begin{tabular}{|c|c|c|c|c|c|c|}
\hline \multicolumn{7}{|c|}{ Table 2} \\
\hline & $\begin{array}{l}\text { British } \\
\text { pound }\end{array}$ & $\begin{array}{c}\text { French } \\
\text { franc }\end{array}$ & $\begin{array}{l}\text { D eutsche } \\
\text { mark }\end{array}$ & $\begin{array}{l}\text { Swiss } \\
\text { franc }\end{array}$ & Yen & $\begin{array}{l}\text { US } \\
\text { Dollar }\end{array}$ \\
\hline British pound & 1 & 0.41 & 0.41 & 0.61 & 0.65 & 0.49 \\
\hline French franc & 0.27 & 1 & 0.87 & 0.72 & 0.26 & 0.15 \\
\hline Deutsche mark & 0.27 & 0.73 & 1 & 0.82 & 0.14 & 0.09 \\
\hline Swiss franc & 0.46 & 0.62 & 0.76 & 1 & 0.44 & 0.17 \\
\hline Yen & 0.54 & 0.35 & 0.29 & 0.47 & 1 & 0.20 \\
\hline US dollar & 0.32 & 0.41 & 0.20 & 0.32 & 0.30 & 1 \\
\hline
\end{tabular}

Note: The lower triangular matrix shows contemporaneous correlations between slopes for the 1984-1998 sample. The upper triangular matrix shows correlations for the 1991-1998 subsample. 
Table 3

Principal components in eurocurrency slopes

Panel a: Eigenvectors of covariance matrix of slopes

\begin{tabular}{|c|cccccc}
\hline & British pound & French franc & Deutsche mark & Swiss franc & Yen & US dollar \\
\hline First eigenvector & -.2077 & -.6211 & -.6162 & -.2691 & -.1044 & -.3300 \\
Second eigenvector & .8481 & -.3844 & -.0105 & -.1380 & .2217 & .2543 \\
Third eigenvector & -.2739 & -.5432 & .7463 & -.2616 & -.0586 & .0324 \\
Fourth eigenvector & .2712 & .0679 & .2424 & .1114 & .1951 & -.9014 \\
\hline
\end{tabular}

Panel b: R-squared coefficients on individual principal components

\begin{tabular}{|c|cccccc|}
\hline & British pound & French franc & Deutsche mark & Swiss franc & Yen & US dollar \\
\hline On first component & .1843 & .7740 & .7589 & .4945 & .2196 & .3639 \\
On second component & .6729 & .0814 & .0004 & .0434 & .1736 \\
On third component & .0655 & .1193 & .2595 & .1013 & .0131 \\
On fourth component & .1307 & .0768 & .1033 & .1731 & .0144 \\
\hline
\end{tabular}

Panel c: R-squared coefficients on subsets of principal components

\begin{tabular}{|c|cccccc|}
\hline & British pound & French franc & Deutsche mark & Swiss franc & Yen & US dollar \\
\hline On first component & .1764 & .7950 & .7628 & .5174 & .2390 & .3639 \\
On first two components & .8762 & .8429 & .7689 & .5307 & .4036 & .4405 \\
On first three components & .9527 & .9836 & .9883 & .6476 & .4216 & .4499 \\
On first four components & .9851 & .9836 & .9997 & .6899 & .4489 & .9964 \\
\hline
\end{tabular}




\begin{tabular}{|c|c|c|c|c|c|c|c|c|c|c|c|c|}
\hline \multicolumn{13}{|c|}{$\begin{array}{c}\text { Table } 4 \\
\text { Estimated models }\end{array}$} \\
\hline \multirow{2}{*}{$\begin{array}{l}0 \text { wn lags } \\
i=1\end{array}$} & \multicolumn{2}{|c|}{ British pound } & \multicolumn{2}{|c|}{ French franc } & \multicolumn{2}{|c|}{ Deutsche mark } & \multicolumn{2}{|c|}{ Swiss franc } & \multicolumn{2}{|c|}{ Yen } & \multicolumn{2}{|c|}{ US dollar } \\
\hline & $\begin{array}{c}1.144 \\
(0.076)\end{array}$ & & $\begin{array}{c}0.891 \\
(0.076)\end{array}$ & & $\begin{array}{c}0.603 \\
(0.078)\end{array}$ & & $\begin{array}{c}0.832 \\
(0.076)\end{array}$ & & $\begin{array}{c}0.656 \\
(0.075)\end{array}$ & & $\begin{array}{c}0.921 \\
(0.078)\end{array}$ & \\
\hline$i=2$ & $\begin{array}{c}-0.472 \\
(0.111)\end{array}$ & & $\begin{array}{c}-0.253 \\
(0.101)\end{array}$ & & $\begin{array}{c}0.178 \\
(0.090)\end{array}$ & & $\begin{array}{c}0.102 \\
(0.099)\end{array}$ & & $\begin{array}{c}-0.052 \\
(0.090)\end{array}$ & & $\begin{array}{c}-0.062 \\
(0.106)\end{array}$ & \\
\hline$i=3$ & $\begin{array}{c}0.218 \\
(0.076) \\
\end{array}$ & & $\begin{array}{c}0.215 \\
(0.074) \\
\end{array}$ & & $\begin{array}{c}0.015 \\
(0.078) \\
\end{array}$ & & $\begin{array}{c}-0.023 \\
(0.077) \\
\end{array}$ & & $\begin{array}{c}0.232 \\
(0.075) \\
\end{array}$ & & \begin{tabular}{|l}
-0.027 \\
$(0.078)$ \\
\end{tabular} & \\
\hline First component & & $\begin{array}{l}-0.202 \\
(0.005)\end{array}$ & & $\begin{array}{l}-0.635 \\
(0.007)\end{array}$ & & $\begin{array}{l}-0.614 \\
(0.001)\end{array}$ & & $\begin{array}{l}-0.236 \\
(0.017)\end{array}$ & & $\begin{array}{l}-0.126 \\
(0.016)\end{array}$ & & $\begin{array}{r}-0.330 \\
(0.002)\end{array}$ \\
\hline Second component & & $\begin{array}{c}0.843 \\
(0.010)\end{array}$ & & $\begin{array}{c}-0.377 \\
(0.015)\end{array}$ & & $\begin{array}{c}-0.012 \\
(0.002)\end{array}$ & & $\begin{array}{c}-0.155 \\
(0.033)\end{array}$ & & $\begin{array}{c}0.243 \\
(0.031)\end{array}$ & & $\begin{array}{r}0.255 \\
(0.004)\end{array}$ \\
\hline Third component & & $\begin{array}{l}-0.278 \\
(0.010)\end{array}$ & & $\begin{array}{c}0.554 \\
(0.016)\end{array}$ & & $\begin{array}{c}0.745 \\
(0.002)\end{array}$ & & $\begin{array}{l}-0.239 \\
(0.035)\end{array}$ & & $\begin{array}{l}-0.048 \\
(0.033)\end{array}$ & & $\begin{array}{r}0.035 \\
(0.004)\end{array}$ \\
\hline Fourth component & & $\begin{array}{r}0.289 \\
(0.015) \\
\end{array}$ & & $\begin{array}{c}0.012 \\
(0.022) \\
\end{array}$ & & $\begin{array}{c}0.248 \\
(0.003) \\
\end{array}$ & & $\begin{array}{c}0.243 \\
(0.050) \\
\end{array}$ & & $\begin{array}{r}0.112 \\
(0.047) \\
\end{array}$ & & $\begin{array}{r}-0.900 \\
(0.006) \\
\end{array}$ \\
\hline $\begin{array}{l}\bar{R}^{2} \\
\text { SEE }\end{array}$ & $\begin{array}{l}0.804 \\
0.294\end{array}$ & $\begin{array}{l}0.985 \\
0.081\end{array}$ & $\begin{array}{l}0.721 \\
0.502\end{array}$ & $\begin{array}{l}0.983 \\
0.122\end{array}$ & $\begin{array}{l}0.571 \\
0.622\end{array}$ & $\begin{array}{l}0.999 \\
0.018\end{array}$ & $\begin{array}{l}0.817 \\
0.208\end{array}$ & $\begin{array}{l}0.683 \\
0.274\end{array}$ & $\begin{array}{l}0.600 \\
0.223\end{array}$ & $\begin{array}{l}0.461 \\
0.389\end{array}$ & $\begin{array}{l}0.717 \\
0.266\end{array}$ & $\begin{array}{l}0.996 \\
0.031\end{array}$ \\
\hline
\end{tabular}

Note: The left column in each panel contains estimates of an AR(3) model, while the right column present estimates of the projection on the first four principal components. A constant (generally non-significant) was included in all models. $\bar{R}^{2}$ and SEE denote the coefficient of determination, adjusted for degrees of freedom, and Standard Error of Estimate of each regression, respectively. 


\begin{tabular}{|c|c|c|c|c|c|c|c|c|c|c|c|c|c|c|}
\hline \multicolumn{15}{|c|}{$\begin{array}{c}\text { Tabla } 5 \\
\text { Forecasting performance indicators }{ }^{\mathrm{a}}\end{array}$} \\
\hline & \multicolumn{3}{|c|}{ British pound } & \multicolumn{3}{|c|}{ French franc } & \multicolumn{2}{|c|}{ Deutsche mark } & \multicolumn{2}{|c|}{ Swiss franc } & \multicolumn{2}{|c|}{ Yen } & \multicolumn{2}{|c|}{ US dollar } \\
\hline \multirow{3}{*}{$\begin{array}{c}\text { Sample absolute mean values }{ }^{b} \\
1998: 1-1998: 12\end{array}$} & \multicolumn{3}{|c|}{0.268} & \multicolumn{3}{|c|}{0.264} & \multicolumn{2}{|c|}{0.249} & \multicolumn{2}{|c|}{0.288} & \multicolumn{2}{|c|}{0.068} & \multicolumn{2}{|c|}{0.213} \\
\hline & \multicolumn{3}{|c|}{$\begin{array}{c}\text { Levels } \\
\text { Forecasting model }\end{array}$} & \multicolumn{3}{|c|}{$\begin{array}{c}\text { Differences } \\
\text { Forecasting model }\end{array}$} & \multicolumn{2}{|c|}{$\begin{array}{c}\text { Differences } \\
\text { Forecasting model }\end{array}$} & \multicolumn{2}{|c|}{$\begin{array}{c}\text { Differences } \\
\text { Forecasting model }\end{array}$} & \multicolumn{2}{|c|}{$\begin{array}{c}\text { Differences } \\
\text { Forecasting model }\end{array}$} & \multicolumn{2}{|c|}{$\begin{array}{c}\text { Differences } \\
\text { Forecasting mode }\end{array}$} \\
\hline & $A R(3)$ & One & Two & $A R(3)$ & One & Two & $A R(3)$ & One & $A R(3)$ & One & $A R(3)$ & One & $A R(3)$ & One \\
\hline \multicolumn{15}{|l|}{ Static forecasts ${ }^{c}$} \\
\hline M ean & 0.163 & 0.251 & 0.187 & 0.070 & 0.069 & 0.060 & 0.181 & 0.164 & 0.073 & 0.070 & 0.058 & 0.057 & 0.135 & 0.133 \\
\hline Median & 0.107 & 0.190 & 0.164 & 0.066 & 0.065 & 0.042 & 0.087 & 0.113 & 0.055 & 0.045 & 0.043 & 0.031 & 0.067 & 0.072 \\
\hline RM SE & 0.208 & 0.331 & 0.210 & 0.085 & 0.087 & 0.081 & 0.255 & 0.215 & 0.094 & 0.089 & 0.073 & 0.082 & 0.183 & 0.177 \\
\hline U & 0.965 & 0.964 & 0.938 & 0.954 & 0.949 & 0.949 & 0.921 & 0.949 & 0.948 & 0.952 & 0.897 & 0.875 & 0.959 & 0.960 \\
\hline Dynamic forecasts & & & & \multicolumn{3}{|c|}{ Levels } & & & & & & & & \\
\hline Mean & 0.341 & 0.281 & 0.309 & 0.126 & 0.236 & 0.150 & 0.229 & 0.215 & 0.159 & 0.138 & 0.070 & 0.070 & 0.187 & 0.192 \\
\hline Median & 0.173 & 0.162 & 0.144 & 0.083 & 0.253 & 0.167 & 0.073 & 0.130 & 0.072 & 0.063 & 0.064 & 0.064 & 0.121 & 0.150 \\
\hline RM SE & 0.446 & 0.405 & 0.439 & 0.167 & 0.256 & 0.178 & 0.353 & 0.314 & 0.241 & 0.204 & 0.074 & 0.093 & 0.260 & 0.253 \\
\hline U & 0.982 & 0.976 & 0.981 & 0.867 & 0.663 & 0.819 & 0.841 & 0.861 & 0.804 & 0.834 & 0.861 & 0.788 & 0.957 & 0.951 \\
\hline
\end{tabular}

Notes: a) The left column in each panel shows performance measures for univariate forecasts. The remaining columns contain performance measures for principal components models.

b) M ean absolute values of the slope over the forecasting horizon, 1998:01-1998:12.

c) Mean and Median are the mean and median absolute values of the forecasting errors. RM SE denotes the Root M ean Square Error, while U denotes Theil's statistic.

d) 0 ne or Two refer to the number of principal components used in the slope regression model 